\title{
PEMANTAUAN RUANG INKUBATOR PENETASAN TELUR AYAM DENGAN BERBASIS TELEMETRI MENGGUNAKAN ARDUINO UNO R3
}

\author{
Sofyan Shafiudin*, Fida Jazilatur Rohma, Abdilla Eka Prasetya, \\ Rifqi Firmansyah \\ Jurusan Teknik Elektro, Fakultas Teknik, Universitas Negeri Surabaya \\ "Corresponding author, e-mail : Sofyanshafiudin@gmail.com
}

\begin{abstract}
Abstrak-Kebutuhan akan data mengenai kondisi lingkungan sekitar telah mendorong manusia untuk membuat alat yang bisa mengukur kondisi lingkungan. Salah satu hal yang bisa menjelaskan mengenai kondisi lingkungan adalah suhu. Pada penelitian ini, dirancang suatu perangkat yang dapat mengukur suhu pada inkubator penetasan telor ayam dan mengirimkan data yang berupa suhu secara telemetri. Perangkat ini dapat mengirimkan data dari jarak jauh dan pada waktu kapanpun data tersebut dibutuhkan, sehingga memudahkan seseorang dalam memantau inkubator telor ayam tanpa harus selalu menjaganya. Penelitian ini dilakukan dengan cara merancang, membuat, dan melakukan uji coba sistem telemetri yang terdiri dua bagian utama yakni transmitter dan receiver. Pada bagian transmitter terdiri komponen sensor suhu, Arduino Uno R3, dan RF Module Board 433 MHz, sedangkan bagian receiver terdiri atas Arduino Uno R3, laptop, dan RF Module Board 433 MHz. Fungsi utama Arduino Uno R3 adalah sebagai pemroses data dari sensor suhu dan mengirimkan data kepada receiver. Berdasarkan hasil penelitian ketika transmitter dan receiver diletakkan dalam kondisi ruangan tanpa penghalang ( terdapat celah ), sistem dapat berjalan dengan baik dan tidak terjadi kesalahan dalam jangkauan jarak maksimal 8 meter. Sedangkan, ketika transmitter dan receiver diletakkan dengan terhalang dinding sepenuhnya, diperoleh sistem tidak dapat berjalan dengan baik, walaupun jaraknya dekat 1 meter.
\end{abstract}

\section{Kata kunci : Telemetri, Sensor Suhu, Arduino Uno R3, Transmitter \& Receiver}

\begin{abstract}
The need for data on environmental conditions around has been encouraging people to create a tool that can measure environmental conditions. One thing that could explain the environmental condition is temperature. In this study, designed a device that can measure the temperature in the incubator hatching chicken eggs and transmit data such as temperature telemetry. These devices can transmit data remotely and at any time the data is needed, making it easier for someone to monitor chicken egg incubator without always keeping. This research was done by designing, manufacturing, and testing telemetry system which consists of two main parts namely the transmitter and receiver. In the transmitter section consists of components temperature sensors, Arduino Uno R3 and RF Module Board $433 \mathrm{MHz}$, while the receiver section consists of an Arduino Uno R3, laptops, and RF $433 \mathrm{MHz}$ Module Board. The main function of Arduino Uno R3 is as processing data from temperature sensors and sends the data to the receiver. Based on research results when transmitter and receiver are placed in ambient conditions without barriers (there are gaps), the system can run properly and there is no error in the distance range up to 8 meters. Meanwhile, when the transmitter and receiver placed entirely unobstructed walls, obtained by the system can not run well, although the distance is close to 1 meter.
\end{abstract}

Keywords : Telemetry, Temperature Sensor, Arduino Uno R3, Transmitter \& Receiver

Copyright $\odot 2016$ JNTE. All rights reserved

\section{PENDAHULUAN}

Setiap hari manusia memerlukan kondisi suhu yang stabil baik untuk kenyamanan mereka dalam beraktifitas maupun untuk kelancaran pekerjaan mereka yang membutuhkan kestabilan suhu seperti di bidang industri, pertanian ataupun ilmu pengetahuan. Kestabilan suatu temperatur ruangan dirasa kurang efektif jika harus dilakukan monitoring secara konvensional atau manual. Sistem pengendalian suhu juga merupakan hal yang penting di bidang peternakan. Terlebih lagi untuk budi daya telor ayam yang butuh kestabilan suhu ruang pengeraman telor. Pengendalian secara manual sudah tidak lagi efisien karena akan 
membutuhkan banyak waktu. Oleh sebab itu dibutuhkan sebuah terobosan baru untuk memonitoring suhu ruangan inkubator selama 24 jam nonstop. [1]

Untuk memudahkan pengambilan data suhu diperlukan suatu alat yang dapat menginformasikan keadaan tersebut secara terus menerus yaitu dengan data akuisisi menggunakan computer. [2]

Solusi yang dibutuhkan untuk mengatasi permasalahan tersebut adalah dengan memberikan sebuah sistem pendeteksi suhu ruangan berbasis telemetri yang bisa bekerja secara nonstop memonitoring suhu ruang pengeraman telor ayam karena dengan keadaan suhu lingkungan yang mudah berubah ataupun adanya mati lampu penghangat. Perangkat Telemetri yang terdiri dari hardware dan software, dimana perangkat ini terdapat bagian transmitter dan receiver. Pada bagian transmitter terdapat sensor suhu LM35 yang akan terintegrasi dengan Arduino Uno R3 yang kemudian ditransmisikan menggunakan perangkat RF Module Board 433 MHz. Dan pada bagian penerima akan langsung dihubungkan dengan RF Module Board 433 $\mathrm{MHz}$ dimana module tersebut berperan sebagai receiver yang kemudian data akan diproses oleh Arduino Uno R3 dan data dari Arduino Uno R3 tersebut akan ditampilkan pada laptop. [3]

\section{TINJAUAN PUSTAKA}

\subsection{Pengertian Telemetri}

Telemetri adalah sebuah sistem pengendalian dan pengukuran data yang melalui media komunikasi jarak jauh dengan menggunakan kabel ataupun wireless. Telemetri terdiri dari beberapa bagian pendukung seperti sensor, saluran transmisi, variabel yang diukur , receiver dan display. [4]

\subsection{Sensor Suhu}

Sensor suhu LM35 adalah sebuah IC yang digunakan untuk mengetahui suhu ruangan dalam bentuk besaran elektrik . Gambar sensor suhu LM 35 dapat ditunjukkan pada Gambar 1.

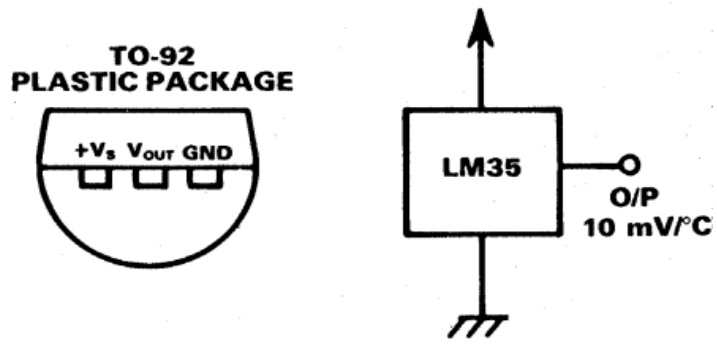

Gambar 1. Sensor Suhu LM35 [5]

Karakteristik Sensor suhu IC LM 35 [6] adalah sebagai berikut :

a. Memiliki sensitivitas suhu, dengan faktor skala linier $10 \mathrm{mVolt} /{ }^{\circ} \mathrm{C}$, sehingga dapat dikalibrasi langsung dalam celcius.

b. Memiliki ketepatan atau akurasi kalibrasi yaitu $0,5^{\circ} \mathrm{C}$ pada suhu $25^{\circ} \mathrm{C}$.

c. Memiliki jangkauan maksimal operasi suhu antara $-55^{\circ} \mathrm{C}$ sampai $+150^{\circ} \mathrm{C}$.

d. Bekerja pada tegangan 4 sampai 30 volt.

e. Memiliki arus rendah yaitu kurang dari 60 $\mu \mathrm{A}$.

f. Memiliki pemanasan sendiri yang rendah (low-heating) yaitu kurang dari $0,1^{\circ} \mathrm{C}$ pada udara diam.

g. Memiliki impedansi keluaran yang rendah yaitu $0,1 \mathrm{~W}$ untuk beban $1 \mathrm{~mA}$.

\subsection{Arduino Uno R3}

Arduino Uno R3 adalah board sistem minimum berbasis mikrokontroller ATmega328P jenis AVR. Arduino Uno R3 memiliki 14 digital input/output (6 diantaranya dapat digunakan untuk PWM output), 6 analog input, $16 \mathrm{MHz}$ osilator kristal, USB connection, power jack, ICSP header dan tombol reset. Gambar Arduino Uno R3 dari atas dapat ditunjukkan pada Gambar 2. Karekteristik dari Arduino Uno R3 [7] adalah sebagai berikut:

- Operating voltage 5 VDC.

- Rekomendasi input voltage 7-12 VDC

- Batas input voltage 6-20 VDC.

- Memiliki 14 buah input/output digital.

- Memiliki 6 buah input analog.

- DC Current setiap I/O Pin sebesar 40mA.

- DC Current untuk 3.3V Pin sebesar 50mA.

- Flash memory $32 \mathrm{~KB}$.

- SRAM sebesar $2 \mathrm{~KB}$.

- EEPROM sebesar $1 \mathrm{~KB}$.

- 11 Clock Speed $16 \mathrm{MHz}$. 


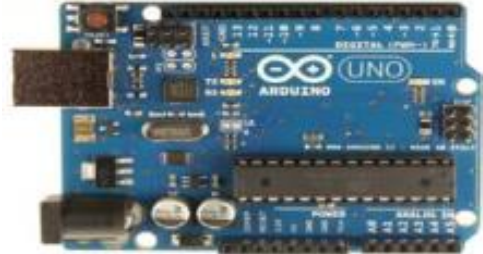

Gambar 2. Arduino Uno R3 [8]

\subsection{RF Module Board $433 \mathrm{MHz}$}

Modul Radio Frekuensi yang digunakan adalah RF Module Board $433 \mathrm{MHz}$ transmitter dan RF Module Board $433 \mathrm{MHz}$ receiver. Modul ini bekerja pada frekuensi $433.92 \mathrm{MHz}$. Spesifikasinya:

Pada bagian receiver [9]

- Model : MX-05V

- Suply Tegangan : DC5V

- Arus : $4 \mathrm{~mA}$

- Frekuensi : $433.92 \mathrm{MHz}$

- Sensitifitas : $105 \mathrm{~dB}$

- Antena $\quad: 32 \mathrm{~cm}$

- Ukuran : $30 * 14 * 7 \mathrm{~mm}$

Pada bagian transmitter [9]

- Model

: MX-FS-03V

- Tegangan

$: 3.5-12 \mathrm{~V}$

- Ukuran

$: 19 * 19 \mathrm{~mm}$

- Mode Kerja

: AM

- Kecepatan Transmisi

$: 4 \mathrm{~KB} / \mathrm{S}$

- Daya Transmisi

$: 10 \mathrm{~mW}$

- Frekuensi

$: 433 \mathrm{MHz}$

- Attenna

$: 25 \mathrm{~cm}$

- Pin (DATA, VCC, GND)

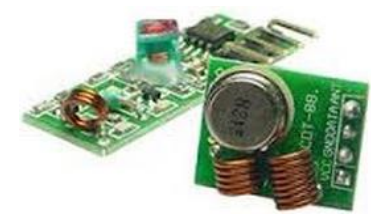

Gambar 3. RF Module Board 433 MHz [10]

\subsection{Kabel USB}

Kabel USB dapat berfungsi sebagai antar muka antara Arduino Uno R3 dengan pemrograman atau komunikasi komputer. [11]

Pada bagian transmitter kabel USB dapat berfungsi sebagai penghubung antara Arduino Uno R3 dengan laptop untuk memasukkan program, selain itu juga berfungsi sebagai supply tegangan dari laptop ke Arduino Uno R3. Dan pada bagaian receiver selain berfungsi sebagai supply tegangan pada Arduino Uno R3, kabel

USB dapat berfungsi sebagai antar muka antara Arduino R3 dengan laptop, dimana pada laptop akan menampilkan data yang dikirim dari Arduino Uno R3 transmitter. Kabel USB dapat ditunjukkan pada Gambar 4 sebagai berikut.

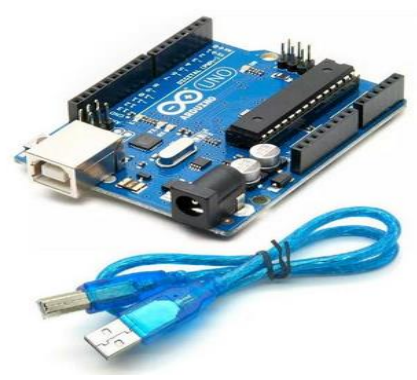

Gambar 4. Kabel USB [12]

\subsection{Ruang Inkubator}

Ruang inkubator berfungsi sebagai tempat untuk pengambilan data dengan memanfaatkan variabel suhu menggunakan 2 bohlam lampu masing - masing memiliki daya 10 Watt, 15 Watt, dan 25 Watt dengan system control ON/OFF seperti Gambar 5.

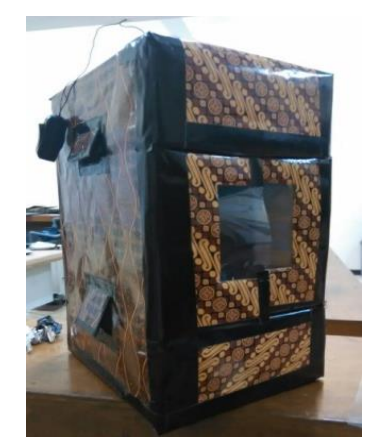

Gambar 5. Ruang Inkubator

\subsection{Relay 5V}

Relay adalah komponen listrik yang bekerja berdasarkan prinsip induksi medan elektromagnetis. Jika sebuah penghantar dialiri oleh arus listrik, maka di sekitar penghantar tersebut timbul medan magnet. Medan magnet yang dihasilkan oleh arus listrik tersebut selanjutnya diinduksikan ke logam. [13]

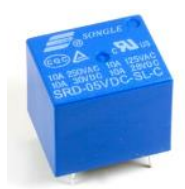

Gambar 6. Relay [14] 


\section{PERANCANGAN SISTEM}

Sistem telemetri dibagi ke dalam dua bagian yaitu transmitter dan receiver. Pada bagian transmitter terdiri dari komponen sensor suhu, Arduino Uno R3, dan RF Module Board 433 $\mathrm{MHz}$, sedangkan pada bagian receiver terdiri atas Arduino Uno R3, laptop, dan RF Module Board 433 MHz. Gambar 7 menunjukkan diagram blok sistem telemetri pemantauan suhu lingkungan dengan menggunakan Arduino Uno R3 dan RF Module Board 433 MHz.

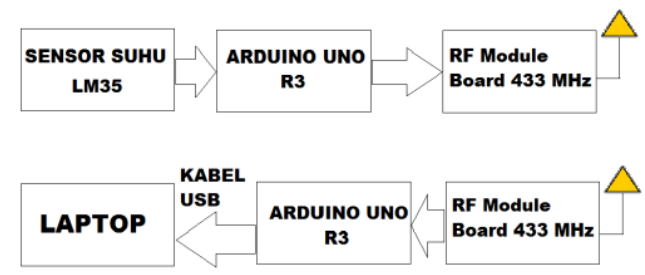

Gambar 7. Blok Diagram Sistem Telemetri

Sistem telemetri secara keseluruhan dalam penelitian, meliputi ruang inkubator, rangkaian sensor LM 35, rangkaian transmitter, dan rangkaian receiver seperti pada Gambar 8.

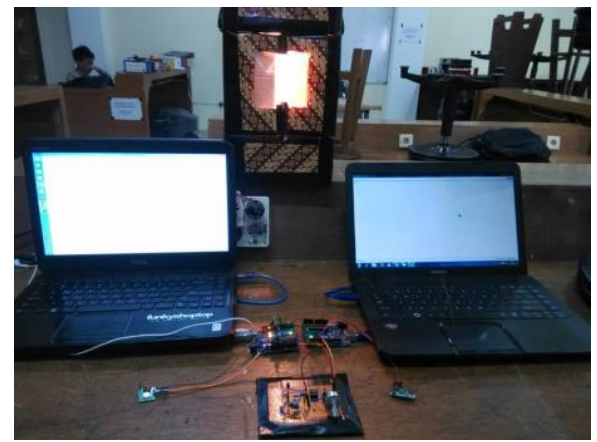

Gambar 8. Rangkaian Telemetri secara Keseluruhan

\subsection{Rangkaian Sensor LM35}

Sensor suhu LM35 adalah komponen elektronika yang memiliki fungsi untuk mengubah besaran suhu menjadi besaran listrik dalam bentuk tegangan. Sensor suhu LM35 juga mempunyai keluaran impedansi yang rendah dan linieritas yang tinggi sehingga dapat dengan mudah dihubungkan dengan rangkaian kendali khusus serta tidak memerlukan penyetelan lanjutan. Sensor LM35 bekerja dengan mengubah besaran suhu menjadi besaran tegangan. Tegangan ideal yang keluar dari
LM35 mempunyai perbandingan $100^{\circ} \mathrm{C}$ setara dengan 1 volt. Sensor ini mempunyai pemanasan diri (self heating) kurang dari $0,1^{\circ} \mathrm{C}$. IC LM 35 sebagai sensor suhu yang teliti dan terkemas dalam bentuk Integrated Circuit (IC), dimana output tegangan keluaran sangat linear terhadap perubahan suhu. Sensor ini berfungsi sebagai pegubah dari besaran fisis suhu ke besaran tegangan yang memiliki koefisien sebesar 10 $\mathrm{mV} /{ }^{\circ} \mathrm{C}$ yang berarti bahwa kenaikan suhu $1^{\circ} \mathrm{C}$ maka akan terjadi kenaikan tegangan sebesar 10 $\mathrm{mV}$. [15]

Pada rangkaian sensor suhu LM35 dapat ditambah dengan IC LM 358, dimana dengan penambahan IC LM 358 dapat memberikan penguatan tegangan keluaran pada sensor LM 35. Rancangan rangkaian dari LM 35 dan LM 358 dapat ditunjukkan pada Gambar 9.

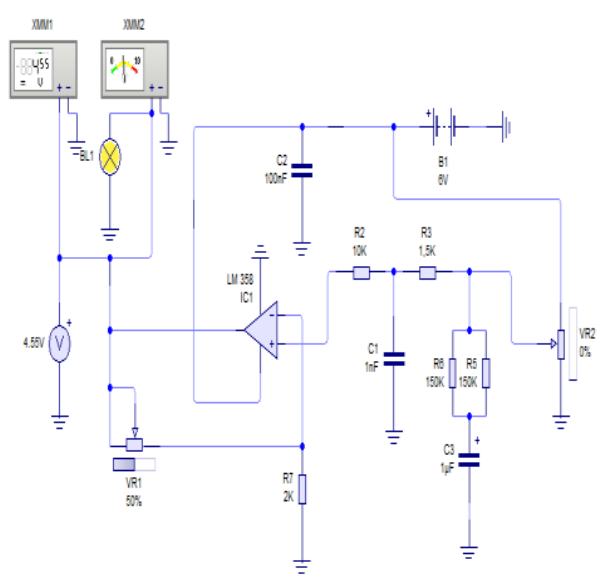

Gambar 9. Rancangan Rangkaian LM 35 dan Penguat LM 358

Dan untuk rangkaian LM 35 beserta penguat LM 358 dalam penelitian Seperti pada Gambar 10.

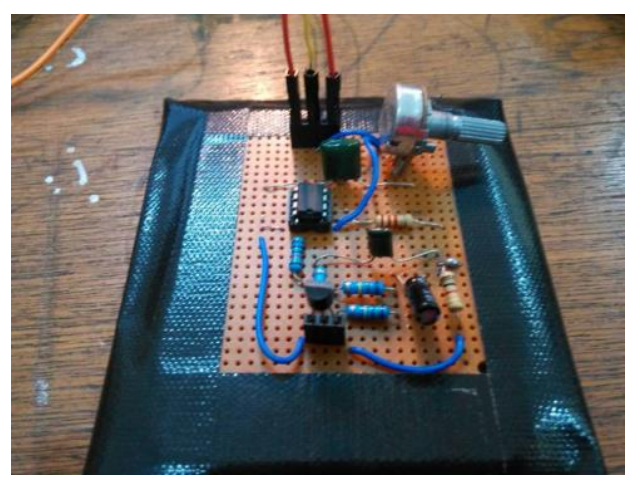

Gambar 10. Rangkaian LM 35 dan Penguat LM 358 pada Penelitian 


\subsection{Rangkaian Transmitter}

Rangkaian transmitter terdiri dari rangkaian sensor suhu LM35, Arduino Uno R3, dan RF Module Board $433 \mathrm{MHz}$ transmitter. Rangkaian sensor suhu LM35 digunakan untuk mengukur temperatur pengukuran tersebut akan diproses oleh Arduino Uno, untuk diolah menjadi suatu data, dan data tersebut akan dikirimkan oleh Arduino Uno R3 pada receiver melalui RF Module Board $433 \mathrm{MHz}$ transmitter. Gambar rancangan rangkaian transmitter dapat dilihat pada Gambar 11.

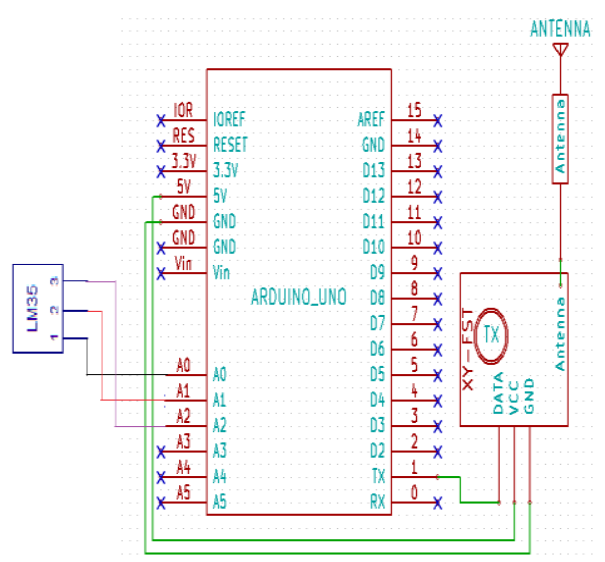

Gambar 11. Rancangan Rangkaian Transmitter [16]

Dan untuk rangkaian transmitter dalam penelitian dapat ditunjukkan pada Gambar 12.

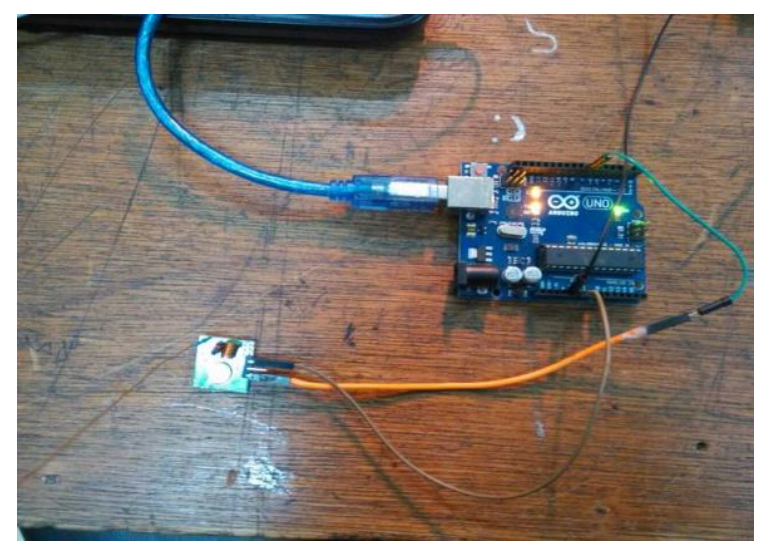

Gambar 12. Rangkaian Transmitter pada Penelitian

\subsection{Rangkaian Receiver}

Rangkaian receiver terdiri dari RF Module Board $433 \mathrm{MHz}$ receiver, Arduino Uno R3, dan penampil berupa laptop. RF Module Board 433
$\mathrm{MHz}$ receiver berfungsi sebagai penerima data data yang dikirim dari transmitter, data yang telah diterima tersebut kemudian akan diproses oleh Arduino Uno R3 dan data tersebut akan ditampilkan pada laptop yang terhubung dengan Arduino Uno R3. Arduino Uno R3 dapat terhubung dengan laptop melalui kabel USB. Gambar dari rancangan rangkaian receiver dapat dilihat pada Gambar 13.

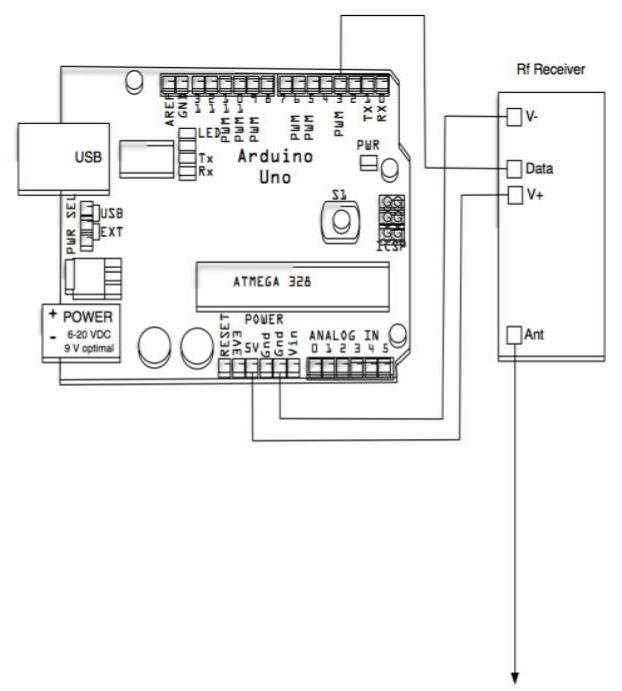

Gambar 13. Rancangan Rangkaian Sistem Receiver [17]

Dan untuk rangkaian receiver dalam penelitian dapat ditunjukkan pada Gambar 14.

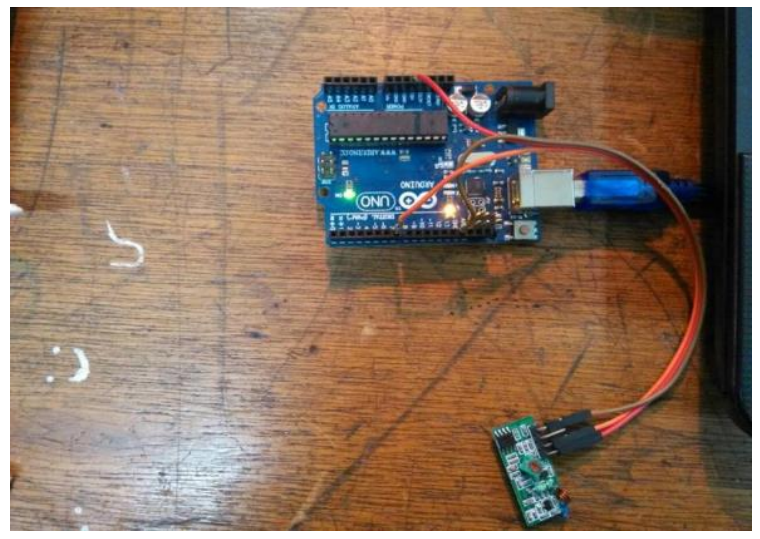

Gambar 14. Rangkaian Transmitter pada Penelitian

\subsection{Rangkaian Sistem Kontroller On / Off}

Rangkaian sistem kontrol On/Off pada inkubator terdiri dari sebuah Relay yang dihubungkan ke Arduino Uno R3 bagian 
transmitter dan lampu. Relay digunakan sebagai pemutus dan penyambung arus listrik. Pada penelitian, relay tersebut digunakan untuk mematikan lampu dan menghidupkan lampu sesuai setpoint yang telah ditetapkan di Program Arduino. Apabila suhu berada diatas setpoint, maka relay akan bekerja untuk mematikan lampu, sedangkan ketika suhu sudah menurun dibawah setpoint yang ditetapkan, maka relay akan bekerja untuk menyalakan lampu ( sebagai kontroller On / Off ). Rangkaian sistem kontroller On / Off dapat ditunjukkan pada Gambar 15.

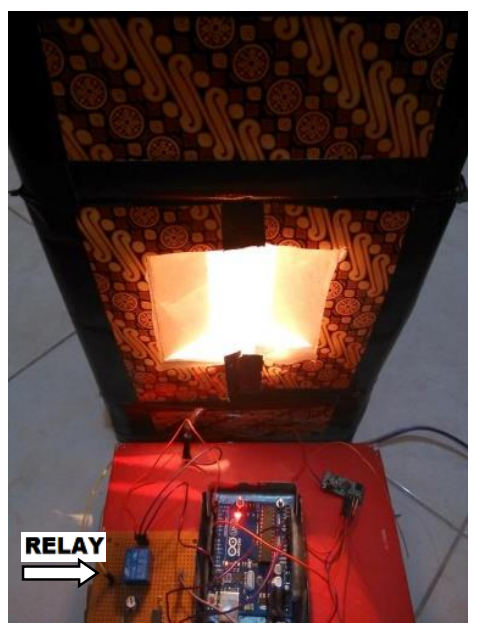

Gambar 15. Sistem kontroler di Inkubator

\section{PENGUJIAN DAN PEMBAHASAN}

\subsection{Pengujian dan Kalibrasi Alat}

Pengujian sensor suhu dilakukan dengan membandingkan alat yang dirancang dengan alat ukur thermometer. Pada pengujian, yang dijadikan sebagai penghasil panas adalah lampu, dimana daya lampu dibuat bervariasi untuk mengetahui suhu yang dapat dihasilkan oleh lampu. Pengujian dan kalibrasi sensor suhu LM 35 dapat dilihat pada Tabel 1.

Tabel 1. Pengujian dan Kalibrasi pada Sensor Suhu LM 35

\begin{tabular}{|c|c|c|c|c|}
\hline No. & Perlakuan & $\begin{array}{c}\text { Pembacaan } \\
\text { Sensor }\end{array}$ & $\begin{array}{c}\text { Pembacaan } \\
\text { Thermometer }\end{array}$ & $\begin{array}{c}\text { Error } \\
\left({ }^{0} \mathrm{C}\right)\end{array}$ \\
\hline 1. & $\begin{array}{c}\text { Lampu } \\
10 \mathrm{Watt}\end{array}$ & 32.85 & 33.4 & 0,55 \\
\hline 2. & $\begin{array}{c}\text { Lampu } \\
15 \mathrm{Watt}\end{array}$ & 34.43 & 35.2 & 0,77 \\
\hline 3. & $\begin{array}{c}\text { Lampu } \\
25 \mathrm{Watt}\end{array}$ & 43.5 & 44.1 & 0,6 \\
\hline
\end{tabular}

Dari data yang diperoleh dapat dilihat suhu yang terukur oleh sensor mendekati suhu yang terukur dengan thermometer, dengan kesalahan maksimal $2^{\circ} \mathrm{C}$.

\subsection{Pengujian Sistem Telemetri}

Pada pengujian sistem telemetri secara keseluruhan digunakan lampu 10 Watt, 15 Watt, dan 25 Watt sebagai panas yang diukur oleh sensor. Gambar 16, dapat ditunjukkan hasil pengujian pada bagian transmitter yang ditampilkan pada laptop.

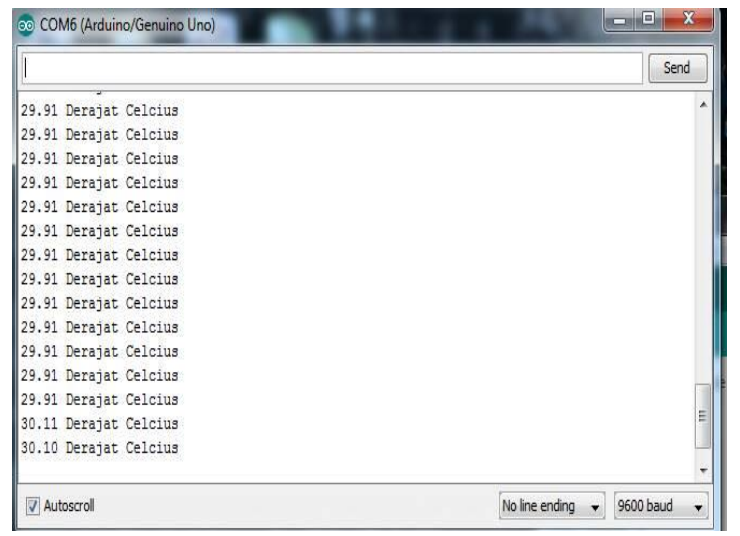

Gambar 16. Tampilan pada Transmitter

Gambar 17, dapat ditunjukkan hasil pengujian pada bagian receiver yang ditampilkan pada laptop.

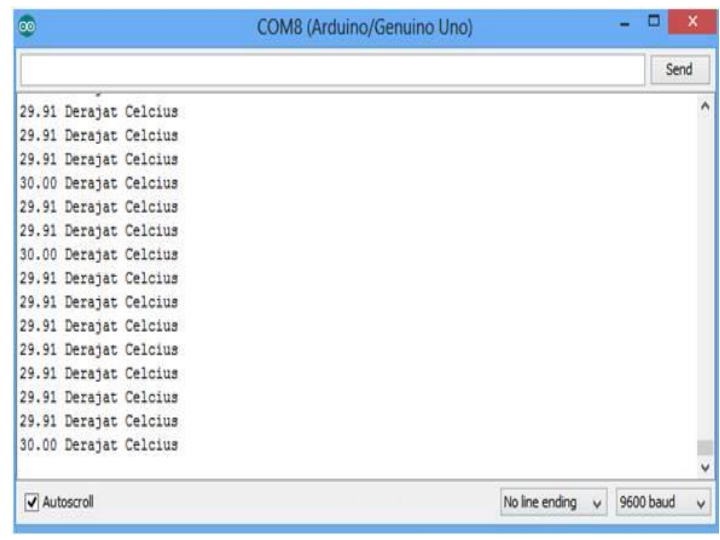

Gambar 17. Tampilan pada Receiver

Tabel 2 menunjukkan perbandingan data suhu yang dikirim dan diterima yang ditampilkan pada laptop dengan kondisi ruangan tanpa penghalang ( terdapat celah ) dengan sumber lampu 10 Watt. 
Tabel 2. Pengujian Sistem Telemetri tanpa Penghalang ( terdapat celah) dengan Sumber Lampu 10 Watt

\begin{tabular}{|c|c|c|c|}
\hline No. & $\begin{array}{c}\text { Data } \\
\text { Dikirim }\end{array}$ & $\begin{array}{c}\text { Data } \\
\text { Diterima }\end{array}$ & $\begin{array}{c}\text { Jarak } \\
\text { (meter) }\end{array}$ \\
\hline 1. & $32,85^{\circ} \mathrm{C}$ & $32,85^{0} \mathrm{C}$ & 1 \\
\hline 2. & $32,85^{\circ} \mathrm{C}$ & $32,85^{\circ} \mathrm{C}$ & 5 \\
\hline 3. & $32,85^{\circ} \mathrm{C}$ & $32,85^{\circ} \mathrm{C}$ & 8 \\
\hline
\end{tabular}

Tabel 3 menunjukkan perbandingan data suhu yang dikirim dan diterima yang ditampilkan pada laptop dengan kondisi ruangan tanpa penghalang ( terdapat celah ) dengan sumber lampu 15 Watt.

Tabel 3. Pengujian Sistem Telemetri tanpa Penghalang ( terdapat celah ) dengan Sumber Lampu 15 Watt

\begin{tabular}{|c|c|c|c|}
\hline No. & $\begin{array}{c}\text { Data } \\
\text { Dikirim }\end{array}$ & $\begin{array}{c}\text { Data } \\
\text { Diterima }\end{array}$ & $\begin{array}{c}\text { Jarak } \\
\text { (meter) }\end{array}$ \\
\hline 1. & $34.43^{\circ} \mathrm{C}$ & $34.43^{\circ} \mathrm{C}$ & 1 \\
\hline 2. & $34.43^{\circ} \mathrm{C}$ & $34.43^{\circ} \mathrm{C}$ & 5 \\
\hline 3. & $34.43^{\circ} \mathrm{C}$ & $34.43^{\circ} \mathrm{C}$ & 8 \\
\hline
\end{tabular}

Tabel 4 menunjukkan perbandingan data suhu yang dikirim dan diterima yang ditampilkan pada laptop dengan kondisi ruangan tanpa penghalang ( terdapat celah ) dengan sumber lampu 25 Watt.

Tabel 4. Pengujian Sistem Telemetri tanpa Penghalang ( terdapat celah) dengan Sumber Lampu 25 Watt tanpa kontroler On/Off .

\begin{tabular}{|c|c|c|c|}
\hline No. & $\begin{array}{c}\text { Data } \\
\text { Dikirim }\end{array}$ & $\begin{array}{c}\text { Data } \\
\text { Diterima }\end{array}$ & $\begin{array}{c}\text { Jarak } \\
\text { (meter) }\end{array}$ \\
\hline 1. & $43,5^{\circ} \mathrm{C}$ & $43,5^{\circ} \mathrm{C}$ & 1 \\
\hline 2. & $43,5^{\circ} \mathrm{C}$ & $43,5^{0} \mathrm{C}$ & 5 \\
\hline 3. & $43,5^{\circ} \mathrm{C}$ & $43,5^{\circ} \mathrm{C}$ & 8 \\
\hline
\end{tabular}

Berdasarkan hasil pengujian dengan transmitter dan receiver diletakkan dalam kondisi ruangan tanpa penghalang ( terdapat celah ), sistem dapat berjalan dengan baik dan tidak terjadi kesalahan dalam jangkauan 8 meter. Pada jarak lebih dari 8 meter, sinyal sudah melemah. Apabila transmitter dan receiver diletakkan pada kondisi terhalang oleh dinding sepenuhnya dengan menggunakan lampu berdaya 10 Watt, maka perbandingan data suhu yang dikirim dan diterima yang ditampilkan pada laptop dapat ditunjukkan pada Tabel 5.
Tabel 5. Pengujian Sistem Telemetri dengan

Kondisi Terhalang Dinding Sepenuhnya ( tanpa celah ) dengan Sumber Lampu 10 Watt

\begin{tabular}{|c|c|c|c|}
\hline No. & $\begin{array}{c}\text { Data } \\
\text { Dikirim }\end{array}$ & $\begin{array}{c}\text { Data } \\
\text { Diterima }\end{array}$ & $\begin{array}{c}\text { Jarak } \\
\text { (meter) }\end{array}$ \\
\hline 1. & $32,85^{\circ} \mathrm{C}$ & - & 1 \\
\hline 2. & $32,85^{\circ} \mathrm{C}$ & - & 5 \\
\hline 3. & $32,85^{\circ} \mathrm{C}$ & - & 8 \\
\hline
\end{tabular}

Tabel 6 menunjukkan perbandingan data suhu yang dikirim dan diterima yang ditampilkan pada laptop dengan kondisi terhalang dinding sepenuhnya ( tanpa celah) dengan sumber lampu 15 Watt.

Tabel 6. Pengujian Sistem Telemetri dengan

Kondisi Terhalang Dinding Sepenuhnya ( tanpa celah ) dengan Sumber Lampu 15 Watt

\begin{tabular}{|c|c|c|c|}
\hline No. & Data Dikirim & $\begin{array}{c}\text { Data } \\
\text { Diterima }\end{array}$ & $\begin{array}{c}\text { Jarak } \\
\text { (meter) }\end{array}$ \\
\hline 1. & $34.43^{\circ} \mathrm{C}$ & - & 1 \\
\hline 2. & $34.43^{\circ} \mathrm{C}$ & - & 5 \\
\hline 3. & $34.43^{\circ} \mathrm{C}$ & - & 8 \\
\hline
\end{tabular}

Tabel 7 menunjukkan perbandingan data suhu yang dikirim dan diterima yang ditampilkan pada laptop dengan kondisi terhalang dinding sepenuhnya ( tanpa celah ) dengan sumber lampu 25 Watt.

Tabel 7. Pengujian Sistem Telemetri dengan

Kondisi Terhalang Dinding Sepenuhnya ( tanpa celah ) dengan Sumber Lampu 25 Watt

\begin{tabular}{|c|c|c|c|}
\hline No. & $\begin{array}{c}\text { Data } \\
\text { Dikirim }\end{array}$ & $\begin{array}{c}\text { Data } \\
\text { Diterima }\end{array}$ & $\begin{array}{c}\text { Jarak } \\
\text { (meter) }\end{array}$ \\
\hline 1. & $43,5^{\circ} \mathrm{C}$ & - & 1 \\
\hline 2. & $43,5^{\circ} \mathrm{C}$ & - & 5 \\
\hline 3. & $43,5^{\circ} \mathrm{C}$ & - & 8 \\
\hline
\end{tabular}

Hasil pengujian kedua dengan transmitter dan receiver diletakkan dengan terhalang dinding sepenuhnya, diperoleh sistem sudah tidak dapat berjalan dengan baik, walaupun jaraknya sangat dekat, yakni 1 meter. Sehingga secara keseluruhan sistem sudah berjalan dengan baik dalam mengirimkan data, hanya saja dengan keterbatasan RF Module Board 433 $\mathrm{MHz}$, maka dalam pengukuran jika ruangan tertutup sepenuhnya, sistem tidak dapat megirimkan data, sehingga membutuhkan suatu celah agar dapat mengirimkan data. Selain itu, jangkauan dari RF Module Board $433 \mathrm{MHz}$ juga 
tidak terlalu jauh, walaupun terdapat celah jangkauan dari RF Module Board $433 \mathrm{MHz}$ hanya 8 meter saja.

Dan berikut ini menunjukkan gambar grafik monitoring suhu pada inkubator.

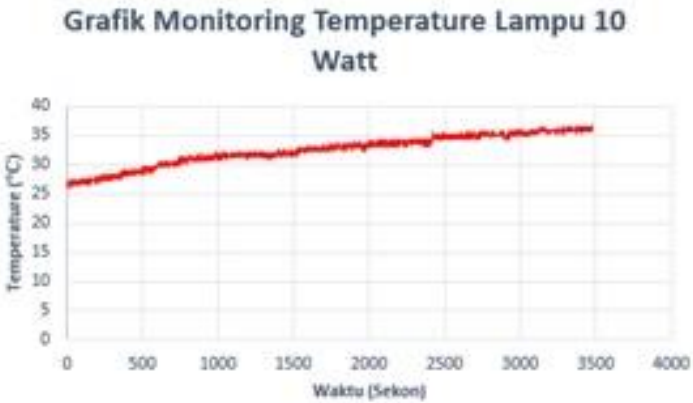

Gambar 18. Grafik Monitoring Temperature Lampu 10 Watt tanpa Menggunakan Relay

Gambar 18 adalah grafik kenaikan suhu di ruang inkubator menggunakan lampu 10 watt. Data yang diambil selama 3500 Sekon menghasilkan kenaikan suhu di dalam inkubator mulai dari suhu $26,4^{\circ} \mathrm{C}$ hingga $36,8^{\circ} \mathrm{C}$.

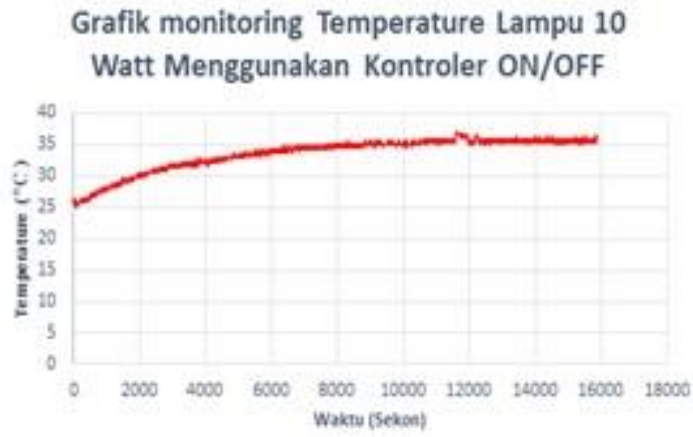

Gambar 19. Grafik Monitoring Temperature Lampu 10 Watt Menggunakan Relay

Gambar 19 adalah grafik kenaikan suhu incubator menggunakan lampu 10 watt dengan kontroler On/Off Otomatis pada ruang incubator . dengan suhu awal pengukuran $25.6^{\circ} \mathrm{C}$ dan suhu puncak $36^{\circ} \mathrm{C}$ selama rentang waktu 15863 sekon - Pada grafik sebelumnya tanpa ada kontroler otomastis relay suhu bisa lebih dari $36^{\circ} \mathrm{C}$. Pada keadaan ini suhu stabil tidak lebih dari $36^{\circ} \mathrm{C}$ karena system relay menghidupkan \& mematikan lampu . Data yang diterima oleh arduino stabil 36 dan secara otomatis berhenti menerima data selama 15863 sekon tanpa mematikan system kerja relay. Apabila suhu berada diatas $36{ }^{\circ} \mathrm{C}$, maka relay akan otomatis mematikan lampu, sedangkan apabila suhu berada dibawah $36{ }^{\circ} \mathrm{C}$, maka relay akan menghidupkan lampu.

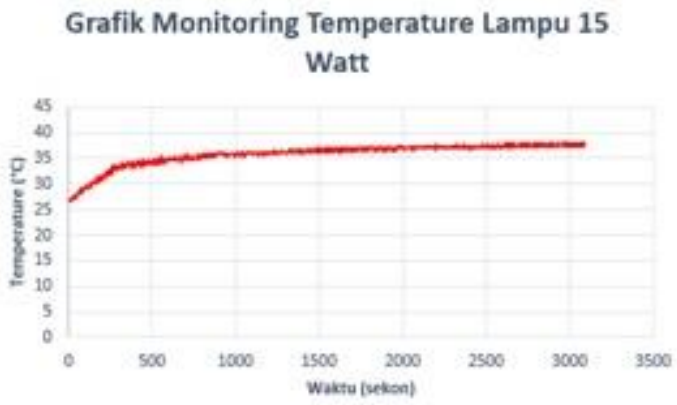

Gambar 20. Grafik Monitoring Temperature Lampu 15 Watt tanpa Menggunakan Relay

Gambar 20 adalah grafik kenaikan suhu di ruang inkubator menggunakan lampu 15 watt .Data yang diambil selama 3099 Sekon menghasilkan kenaikan suhu di dalam inkubator mulai dari suhu kamar $26,8^{\circ} \mathrm{C}$ hingga $38,6^{\circ} \mathrm{C}$.

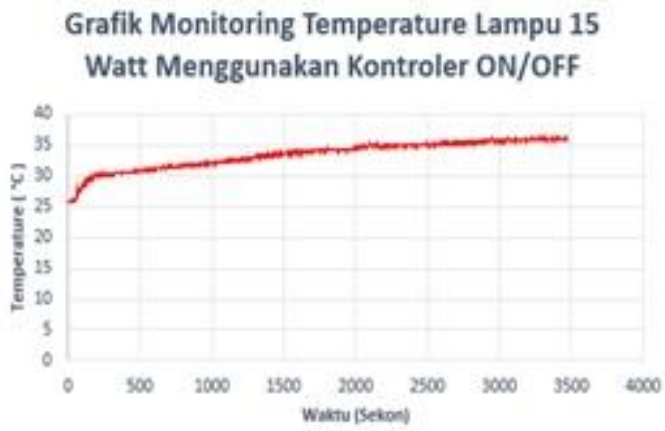

Gambar 21. Grafik Monitoring Temperature Lampu 15 Watt Menggunakan Relay

Gambar 21 adalah grafik kenaikan suhu incubator menggunakan lampu 15 watt dengan kontroler On/Off Otomatis pada ruang incubator.dengan suhu awal pengukuran $25.6{ }^{\circ} \mathrm{C}$ dan suhu puncak $36,4^{\circ} \mathrm{C}$ selama rentang waktu 3500 sekon . Pada grafik sebelumnya tanpa ada kontroler otomastis relay suhu bisa lebih dari 36 ${ }^{\circ} \mathrm{C}$. Pada keadaan ini suhu stabil tidak lebih dari $36,4^{\circ} \mathrm{C}$ karena system relay menghidupkan \& mematikan lampu. Data yang diterima oleh arduino stabil 36 dan secara otomatis berhenti menerima data selama 3500 Sekon tanpa mematikan system kerja relay. Apabila suhu berada diatas $36,4{ }^{\circ} \mathrm{C}$, maka relay akan otomatis 
mematikan lampu, sedangkan apabila suhu berada dibawah $36,4{ }^{\circ} \mathrm{C}$, maka relay akan menghidupkan lampu.

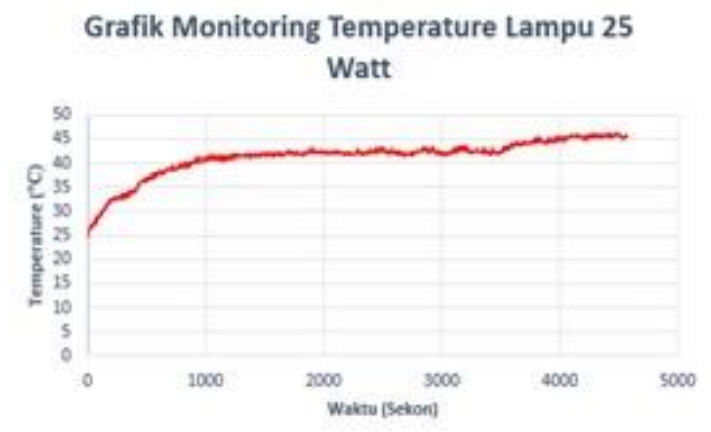

Gambar 22. Grafik Monitoring Temperature Lampu 25 Watt tanpa Menggunakan Relay.

Gambar 22 adalah grafik kenaikan suhu diruang incubator menggunakan lampu 25 watt. Data yang diambil selama 4600 Sekon menghasilkan kenaikan suhu di dalam inkubator mulai dari suhu kamar $24,4^{\circ} \mathrm{C}$ hingga $46^{\circ} \mathrm{C}$.

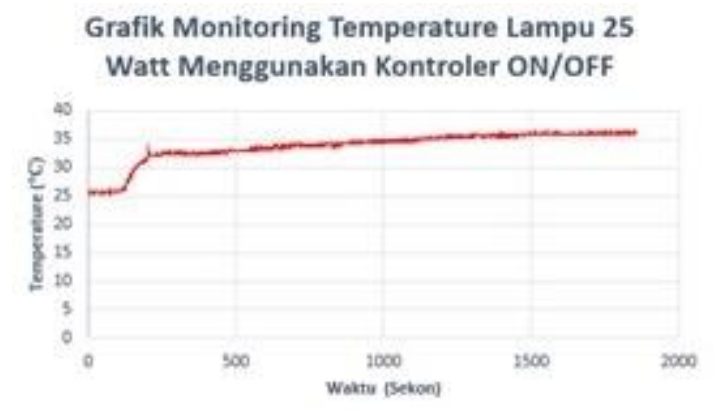

Gambar 23. Grafik Monitoring Temperature Lampu 25 Watt tanpa Menggunakan Relay

Gambar 23 adalah grafik kenaikan suhu incubator menggunakan lampu 25 watt dengan kontroler On/Off Otomatis pada ruang incubator . dengan suhu awal pengukuran $25.6^{\circ} \mathrm{C}$ dan suhu puncak $36,4{ }^{\circ} \mathrm{C}$ selama rentang waktu 1800 sekon . Pada grafik sebelumnya tanpa ada kontroler otomastis relay suhu bisa lebih dari 36 ${ }^{\circ} \mathrm{C}$. Pada keadaan ini suhu stabil tidak lebih dari $36,4^{\circ} \mathrm{C}$ karena system relay menghidupkan \& mematikan lampu . Data yang diterima oleh arduino stabil 36,4 dan secara otomatis berhenti menerima data selama 1800 Sekon tanpa mematikan system kerja relay. Apabila suhu berada diatas $36,4{ }^{\circ} \mathrm{C}$, maka relay akan otomatis mematikan lampu, sedangkan apabila suhu berada dibawah $36,4{ }^{\circ} \mathrm{C}$, maka relay akan menghidupkan lampu.

\section{KESIMPULAN}

Berdasarkan hasil pengujian dapat diperoleh kesimpulan :

1. Sistem telemetri pemantau suhu inkubator dengan sumber lampu pemanas 10 Watt telah berhasil dibuat dengan nilai error suhu maksimal $2^{\circ} \mathrm{C}$.

2. Pada sistem telemetri, jangkauan maksimum adalah 8 meter apabila tanpa penghalang ( masih terdapat celah) dan jika terdapat penghalang sepenuhnya, maka data yang dikirim sudah tidak dapat diterima lagi karena keterbatasan pada alat transmisi.

\section{DAFTAR PUSTAKA}

[1] Hamzah, Amir dkk. Pengukuran Temperatur Ruangan dengan menggunakan Sensor Berbasis Mikrokontroler ( Room Temperature Measurement Using microcontroller Based Sensor). Jurnal Departemen Teknik Sipil dan Lingkungan, Institut Pertanian Bogor.

[2] Aziz, Rofan dan Karsid, September 2015, "Uji Perfomansi Kontrol Suhu Dan Kelembaban Menggunakan Variasi Kontrol Digital Dan Kontrol Schedulling Untuk Pengawetan Buah Dan Sayur". Jurnal Nasional Teknik Elektro Fakultas Teknik Universitas Andalas ISSN : 2302 2949, Vol .4, No.2, http://jnte.ft.unand.ac.id/index.php/first/a rticle/view/166, (9 Februari 2016)

[3] Merry magdalena. 2007. Apa itu Telemetri.https://tigaresi.wordpress.com/ 2007/09/25/apa-itu-telemetri/.(2 Oktober 2015)

[4] Munarso dan Suryono. 2014. Sistem Telemetri Pemantauan Suhu Lingkungan menggunakan Mikrokontroler dan Jaringan Wifi. Youngster Physics Journal ISSN : 2203 - 7371, Vol .3, No.3.

[5] Texas Instruments LM35DZ/NOPB Temperature Sensor 3-Pin TO-92, $0 \rightarrow$ $+100{ }^{\circ} \mathrm{C}$. http://uk.rs- 
online.com/web/p/temperature-humiditysensors/5335907/. (4 Oktober 2015)

[6] Elgattuso. 2015. IC LM 35. https:/elgattuso.wordpress.com/2015/04/ 08/ic-lm35/. (4 Oktober 2015)

[7] Girindra, Prabha. 2015. Arduino Uno R3.http://prabhagib.blogspot.co.id/2015/ 02/arduino-uno-r3.html. (5 Oktober 2015)

[8] Australian Robotics. Arduino Uno R3. http://www.australianrobotics.com.au/pro ducts/arduino-uno-r3. (5 Oktober 2015)

[9] RF Module Board $433 \mathrm{MHz}$ DC 5V Transmitter and Receiver. http://prabhagib.blogspot.co.id/2015/02/a rduino-uno-r3.html. (5 Oktober 2015)

[10] RF Module Board $433 \mathrm{MHz}$ DC 5V Transmitter and Receiver. http://www.iseerobot.com/produk-963-rfmodule-board-433-mhz-dc-5v-transmitter-and-receiver.html.(5 Oktober 2015)

[11] Abid, Dwiki. 2015. Pengertian Fungsi dan Kegunaan Arduino. https://mikro1311860.wordpress.com/20 15/08/19/arduino/. (5 Desember 2015.)

[12] Ihsan. 2015. Pengertian Arduino Uno MikrokontrolerATmega328. http://www.caratekno.com/2015/07/peng ertian-arduino-uno-mikrokontroler.html. (3 Oktober 2015)

[13] Santoso, Hari. 2013. Pengertian, Fungsi, Prinsip, dan Cara Kerja Relay. http://www.elangsakti.com/2013/03/peng ertian-fungsi-prinsip-dan-cara.html. (3 Februari 2016)

[14] Sapkota, Sagar. 2010. How to use a relay. http://www.buildcircuit.com/how-to-usea-relay/. (3 Februari 2016)

[15] Ramdani, Yardi. 2014. Elektronika : Sensor Suhu LM35. http://dhany1412.blogspot.co.id/2014/09/ sensor-suhu-lm35.html. (3 Oktober 2015)

[16] GarageLab. 2013. Project: Ardu-Bot-Tom - RF Link Controlled Robot. http://garagelab.com/profiles/blogs/tutori al-ardubottom-rf-link-controlled-robot. (4 Oktober 2015)

[17] Demay, Vincent. 2014. 433Mhtz RF communication between Arduino and Raspberry $\mathrm{Pi}$ : Arduino as receiver. http://www.homautomation.org/2014/03/ 02/433mhtz-rf-communication-between- arduino-and-raspberry-pi-arduino-asreceiver/. (5 Oktober 2015)

\section{Biodata Penulis}

Sofyan Shafiudin adalah Mahasiswa semester 5 di Program studi S1 Teknik Elektro Universitas Negeri Surabaya bidang keahlian Teknik Sistem Pengaturan dan Instrumentasi

Fida Jazilatur Rohma adalah Mahasiswa semester 5 di Program studi S1 Teknik Elektro Universitas Negeri Surabaya bidang keahlian Teknik Sistem Pengaturan dan Instrumentasi

Abdilla Eka Prasetya adalah Mahasiswa semester 5 di Program studi S1 Teknik Elektro Universitas Negeri Surabaya bidang keahlian Teknik Sistem Pengaturan dan Instrumentasi

Rifqi Firmansyah adalah dosen muda di program studi S1 Teknik Elektro Universitas Negeri Surabaya Bidang keahlian Teknik Sistem Pengaturan dan Instrumentasi . 